\title{
FEASIBILITY OF THE SAR TECHNIQUE ON QUARTZ SAND OF TERRACES OF NW HIMALAYA: A CASE STUDY FROM DEVPRAYAG
}

\author{
MANOJ KUMAR JAISWAL ${ }^{1,2}$, PRADEEP SRIVASTAVA ${ }^{1}$, JAYANT KUMAR TRIPATHI ${ }^{1,3}$ \\ and RAFIQUE ISLAM ${ }^{1}$ \\ ${ }^{I}$ Wadia Institute of Himalayan Geology, 33, General Mahadev Singh road, Dehradun-248001, India \\ ${ }^{2}$ Department of Geosciences, Choushan road, National Taiwan University, Taipei-10617, Taiwan (R.O.C.) \\ ${ }^{3}$ Jawaharlal Nehru University, New Mehrauli road, New Delhi-110067, India
}

Received 6 September 2007

Accepted 2 April 2008

\begin{abstract}
Optically Stimulated Luminescence (OSL) dating technique based on the Single Aliquot Regenerative dose (SAR) protocol is being used increasingly as a means of establishing sediment burial age in the late Quaternary studies. Thermal transfer, low and changing luminescence sensitivity of quartz grains of young sedimentary belts of the New Zealand Alps and the north-east Himalaya poses problems in using SAR protocol. Records of active tectonics and signatures of palaeo-climate are preserved in the Quaternary - Holocene terrace sediments. Therefore, to unfold the history of successive tectonic and palaeo-climate events, robust chronological technique is needed. Palaeoflood deposits in NW Lesser Himalayan region receive quartz from the weathering of various rock types such as quartzite and phyllite in the Alaknanda Basin. A series of tests e.g. dose recovery, preheat plateau, thermal recuperation and change in sensitivity, were performed to check the suitability of quartz grains collected from the terrace sediment of Devprayag of the NW Himalaya, for OSL studies. Inferences were drawn regarding the source of the quartz grains on the basis of the geochemistry and luminescence intensity of the terrace sediment. The study shows that though quartz from the North West Himalaya are low in luminescence intensity but the reproducibility of De value makes the quartz sand suitable for SAR dating technique. Relation between luminescence intensity with CIA values help to predict the provenance of quartz sand. Tests show that the quartz from NW Himalaya is suitable for SAR protocol in OSL.
\end{abstract}

Keywords: OSL, SAR, quartz, NW Himalaya.

\section{INTRODUCTION}

The Himalaya is an active south propagating foldthrust-belt as a result of collision between Indian and Asian plates and preserves signatures of past tectonic and climatic events in the form of various geomorphic archives (Bilham et al., 1997; Senthil et al., 2001; Hodges et al., 2004; Pratt et al., 2004; Burbank, 2005; Wobus et al., 2005). Most of the projects in the Indian Himalayas focused on Lake Sequences for palaeo-climate and neotectonic studies (Singhvi et al., 1994; Banerjee et al. 1999; Chamyal and Juyal, 2005), which can be dated by ${ }^{14} \mathrm{C}$ and less attention was paid to fluvial sediments in the Himalayan river Valleys. Hence no significant OSL

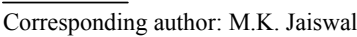

e-mail: mkjosl@gmail.com

ISSN 1897-1695 (online), 1733-8387 (print) (C) 2008 GADAM Centre, Institute of Physics, Silesian University of Technology.

All rights reserved. chronologies are available for the Quaternary sediments of the Indian Himalayas.

Recently, a lot of work has been done regarding the evolution of river terraces and their neo-tectonic and climatic implications (Burbank, 2005; Wobus et al., 2005). Due to lack of suitable organic material and limited upper bound $(<50 \mathrm{ka})$ for ${ }^{14} \mathrm{C}$ dating technique, OSL dating technique was explored due to ubiquitous dating material (Quartz and Feldspar) and expanded upper age limit up to 200-300 ka. Continuous advancement of Optically Stimulated Luminescence (OSL) dating techniques have made this method a robust and popular tool for dating Quaternary sediments from a variety of sedimentary environments e.g. fluvial, aeolian and colluvial. The OSL technique dates the last daylight exposure of the sediment grains before burial and has been widely used to reconstruct past climate and seismic history with their effect on evolution of early man (Srivastava et al., 2003; 
Williams et al., 2006; Juyal et al., 2004; Mukul et al., 2007). Using multiple aliquot additive dose protocol (Aitken, 1998), a few luminescence dates on the fault gouges of Himalaya (Singhvi et al., 1994; Banerjee et al. 1999), lake sequences (Chamyal and Juyal, 2005) and fluvial terraces of Dun valley has been done (Suresh et al., 2002; Singh et al., 2003). However, for fluvial sediments, multiple aliquot protocol of luminescence dating can give rise to inaccurate ages due to partial and heterogeneous bleaching of the sediments before burial. Single aliquot/single grain protocol is the better proven technique for dating partially bleached water lain sediments as it provides the variability in bleaching and thus facilitates to choose the most bleached part of the sediment (Murray and Wintle, 2000).

In the context of high energy fluvial sediment due to topographic control in Himalaya, the Single Aliquot Regeneration (SAR) should be the most preferred protocol of luminescence dating. Using SAR, Jaiswal (2005) explored the partial bleaching in the quartz from sediments of various geomorphic archives e.g. alluvial fan in central Himalaya, palaeoflood from northern Ganga plain, flash flood in NW Himalayas and terraces in Darjeeling Himalayas. The work also highlights the problem of low luminescence counts and changing sensitivity in the Higher Himalayan sediments. Thomas et al., (2007) tested SAR on Quartz from NE Himalayas in Assam, India to bracket the prehistoric earthquakes. The Quartz from that area showed very poor sensitivity. Using SAR, Mukul et al. (2007) dated the Quartz from tectonically uplifted terraces in NE Himalayas in Darjeeling, India. In this study too, the quartz were of low sensitivity and thus single grain studies could not be performed even though the sediments showed poor bleaching history.

During a SAR protocol, an aliquot is measured with various cycles of OSL, irradiation and preheat, which changes the luminescence sensitivity that can produce inaccurate ages. Hence it is important to check that whether the test dose monitors the sensitivity changes or not. Recent studies by Preusser et al. (2006) on luminescence properties of quartz derived from the terraces of New Zealand Alps shows that this quartz show low photon counts and high recuperation effects and thus were not found suitable for optical dating. The low number of cycles of erosion and burial or young sedimentary history was suggested as the probable reason for such luminescence characteristics. Similarly Thomas et al. (2007) studied the luminescence characteristics of the quartz from North-east Himalaya, which has shown low sensitivity. Moska and Murray (2006) have shown weakly sensitized fast component in the quartz from Tatra Mountains from Poland. Therefore the low sensitivity is probably a common problem in the sediments originating in young mountain belts.

Bed loads of the Himalayan Rivers are largely composed of sediments i.e. generated from the weathering of phyllites, granites and gneisses of the lesser and higher Himalayas. However, the relative proportions of the sediments either from granites or phyllites from these rocks vary from place to place and depend upon the local geology, tectonic and climatic conditions. In the present study, geochemical study on the sediments was carried out to infer the source rock or provenance and their composition in the analyzed samples.

The study aims to find out the luminescence properties of quartz in sediment from a particular rock type and its suitability to apply SAR. Quartz was preferred due to fast bleaching rate and apparent absence of fading of luminescence signal. It is also hypothesized that the varying luminescence property should also be a property of mixing of sediments from different sources. The present study is a part of the work done to build up a chronology of tectonic and palaeo-climatic events in NW Himalayas, a major concern towards the understanding of evolution of Himalayas. In this process, the luminescence characteristics of quartz were studied and further evaluated the source of quartz received from different rocks on the basis of luminescence properties. Luminescence chronology and climatic implications has been discussed in detail by Srivastava et al. (2008).

\section{STUDY AREA, SAMPLES AND METHODS}

The Alaknanda River, a major tributary to the Ganga, originates from the Satopanth Glacier situated at the altitude of $3641 \mathrm{~m}$ a.s.l. and meets the Bhagirathi River at Devprayag (541 m a.s.1.). The total catchment area of the Bhagirathi River is $10236.7 \mathrm{~km}^{2}$ and it crosses $229 \mathrm{~km}$ of length (Pal, 1986). The southerly flowing Alaknanda traverses transverse to the east-west tectonic fabric of the Himalayas shows major thrust boundaries and lithotectonic units traversed by the river (Fig. 1).

Chandpur phyllite rocks host and also contribute to the terrace sediments on weathering i.e. mixed with the sediments transported from higher reaches in the river. Phyllite is a low-grade metamorphic rock formed intermediate between slate and schist. The details on the geomorphology, luminescence chronology and climatic interpretations are discussed in detail in Srivastava et al. (2008). In order to determine the source of sediments and the contribution of sediments from the host rock (phyllite) and rocks from the upper reaches (mainly gneisses and granites from Higher Himalayan crystalline rocks), geochemical analysis was carried out.

The Chemical Index of Alteration (CIA) of the sediments is a measure of the extent of chemical weathering and gives insight into the weathering trends (Nesbitt and Young, 1982; Fedo et al., 1995). Four kilograms of each sediment sample was collected, air-dried, homogenized. One kilogram of homogenized sample was crushed to $250 \mu \mathrm{m}$. Out of the $1 \mathrm{~kg}$ sample processed and crushed about $200 \mathrm{~g}$ of each sample was ground to $75 \mu \mathrm{m}$ size for geochemical analysis. The major elements were analyzed by XRF (Siemens) on fused glass disc using the method by Norrish and Hutton (1969). The precision of analysis for major and trace elements were monitored using USGS rock standards (SGR and MAG-1) and were better than $1.5 \%$ and $5 \%$ respectively. Molar proportions of $\mathrm{Al}_{2} \mathrm{O}_{3}$ (A), $\mathrm{CaO}(\mathrm{C}), \mathrm{Na}_{2} \mathrm{O}(\mathrm{N}), \mathrm{K}_{2} \mathrm{O}(\mathrm{K})$ are used for the A-CN$\mathrm{K}$ plots and Chemical Index of Alteration (CIA) (Nesbitt and Young, 1982; 1989), calculation was done on carbonate free basis (see Tripathi and Rajamani, 2003).

For luminescence analysis, unconsolidated sand samples were collected in opaque galvanized iron (GI pipes) 
tubes. These samples were sequentially treated with $10 \%$ $\mathrm{HCl}$ and $30 \% \mathrm{H}_{2} \mathrm{O}_{2}$ to remove carbonates and organic material, then sieved to obtain $90-150 \mu \mathrm{m}$ size fraction. Density separation using Na-Polytungstate $\left(\rho=2.58 \mathrm{~g} / \mathrm{cm}^{3}\right.$ ) was carried out to separate quartz and feldspar minerals. The analysis was done on quartz extract of the sediment. These grains were mounted on stainless steel discs using silicone oil. All the samples were checked for any contamination of feldspar using Infrared Stimulated Luminescence (IRSL). Blue Green Stimulated Luminescence (BGSL) using halogen lamp for stimulation, was carried out on all the samples in Risø TL-DA-15 reader. $\beta$-irradiation was performed using a ${ }^{90} \mathrm{Sr} /{ }^{90} \mathrm{Y}$ source with a dose rate of $3.6 \mathrm{~Gy} /$ minute for coarse grain quartz on stainless steel disk. Luminescence was measured with a Risø TL-DA-15 reader fitted with an EMI 9635 QA photomultiplier tube (PMT) attached to the filter pack consisting of a U-340 filter and BG-39. A total of seven sediment samples (DP-4, DP-7, DP-8, DP- 9, DP- 10, DP-11 and DP-13) from fluvial sediments at Devprayag were measured.

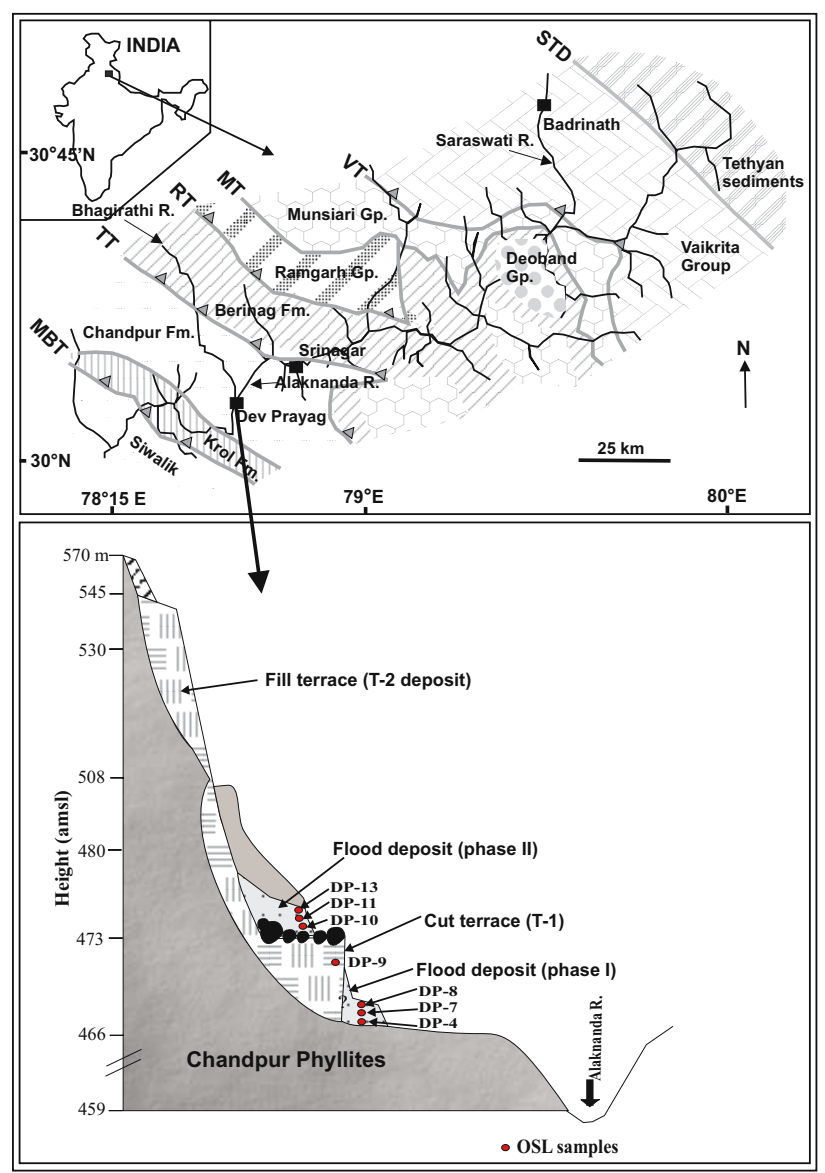

Fig. 1. (a) Location and geological settings of the study site at Deoprayag in NW Himalayas. MBT - Main Boundary thrust, RT - Ramgarh thrust, TT - Tons thrust, VT - Vaikrita thrust and STD - South Tibetan Detachment systems. (b) The sample collection points and their sequences in a geological setting. The site was explored to study the palaeoflood record of the region and to assess the provenance (for details, please see Ahmad et al., 2000).

\section{RESULTS AND DISCUSSION}

\section{Geochemical analysis}

Here we have used the CIA values to characterize the local rocks and their contribution to the sediments comprising of a mixture of sediments from local rocks and the distally transported sediments from the upstream region. The key weathering process in the Himalaya is the physical weathering process due to the high relief, which does not affect the original CIA of the rocks. Phyllite/shales have high CIA and gneisses and granites have lower CIA (Taylor and McLennan, 1985), therefore, the two end members can be used to estimate the relative proportions of the source rocks in the terrace and palaeoflood deposits.

A graph was plotted for present-day channel sediment derived from the hinterland (gneisses and granites), and phyllite bedrock samples in the A-CN-K diagram (Fig. 2). Terraces sediments were plot on the tie line in between. The high CIA value (75) for phyllite and its plot on the A-CN-K space is considered as its original CIA. The mixing line, including all the terrace and palaeoflood sediments, the present day channel sediments and the phyllite bedrock do not follow the normal weathering trend parallel to the A-CN tie line but it intersects A-CN line when extended. This suggests a variable phyllitic contribution to the sediments (Table 1). The chemistry of channel sediments mainly represents the coarse-grained distal sourced sediment component transported as channel sands. Petrographic analysis of sediments indicates that their source area is the Higher Himalayan Crystallines. A chemical mass balance of distal High Himalayas Crystalline and local phyllites at the Deoprayag is made to understand the climato-tectonic conditions in the

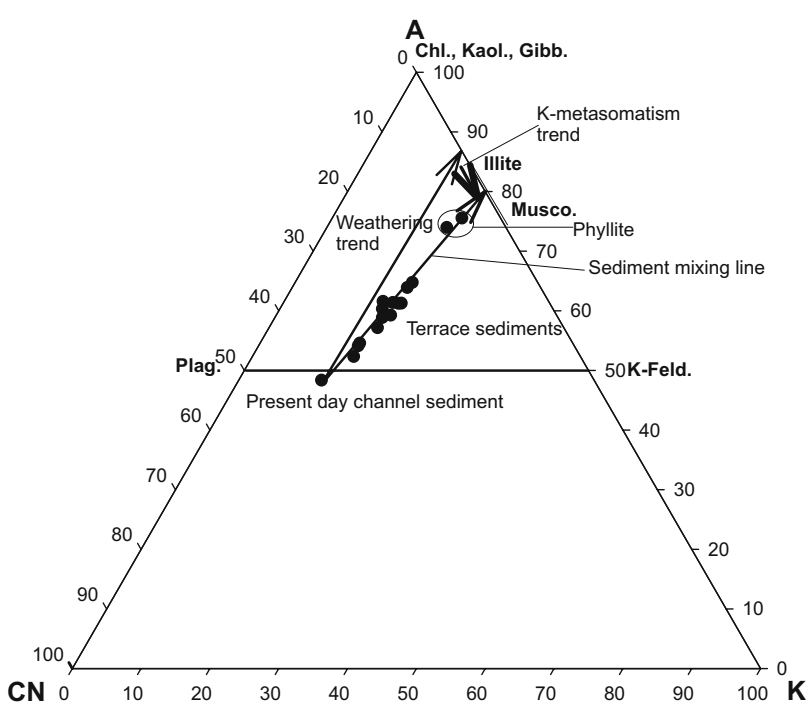

Fig. 2. A-CN-K Plot of the geochemical data of bedrock, present day channel sediment and terrace sediment. Note that the samples plot on the sediment mixing line between present day channel sediment representing upper catchment and bedrock phyllites away from weathering trend. (Modified from Srivastava et al., accepted in Quaternary Research). 
Table 1. The percentage contribution of the local rocks to the sediments selected for study and the background subtracted luminescence counts.

\begin{tabular}{lcc}
\hline Sample & $\begin{array}{c}\text { Phyllitic } \\
\text { composition (\%) }\end{array}$ & $\begin{array}{c}\text { Luminescence counts/ } \\
\text { 20 seconds }\end{array}$ \\
\hline Phyllite rock & 100 & - \\
DP-4 & 33 & 20000 \\
DP-7 & 49 & 13668 \\
DP-8 & 62 & 8134 \\
DP-9 & 49 & 16000 \\
DP-10 & 50 & 14492 \\
DP-11 & 40 & 20507 \\
DP-13 & 49 & 14639 \\
\hline
\end{tabular}

Alakananda River catchment and has been discussed in detail by Srivastava et al. (2008). CIA values suggests that DP-8 has around $62 \%$ of phyllite, DP-4 and DP-11 have $33 \%$ and $40 \%$ phyllite respectively and DP-7, DP-9, DP-10, and DP-13 have phyllitic contribution of around $50 \%$. Any luminescence property of analyzed sediments should reflect the effect of individual contribution of sediments from granitic/gneissic and phyllitic rocks, if they possess different properties.

\section{Luminescence characteristics}

In the standard SAR protocol, the natural luminescence is measured followed by a test dose measurement. A cycle of laboratory doses and their luminescence measurements is made with increasing the dose in each step (Murray and Wintle, 2000). The luminescence yield at each dose point is corrected for sensitivity change by measuring the OSL yield for a test dose at the end of each cycle. A plot of the sensitivity corrected regenerated OSL signal with dose enables the construction of a dose growth curve. Sensitivity corrected natural luminescence intensity is interpolated onto this growth curve to obtain the equivalent dose or palaeodose. The age of the sample is calculated by the simple age formula (Aitken, 1998):

Age $(\mathrm{ka})=\frac{\text { paleodose }(\mathrm{Gy})}{\text { dose accumulated }(\mathrm{Gy} / \mathrm{ka})}$

\section{Luminescence Intensity}

In luminescence dating application, it is important to have a detectable luminescence signal from the sample. Due to poor luminescence counts, large disks $(7 \mathrm{~mm})$ containing up to $\sim 1000$ grains were used for this work. Four aliquots from each sample were bleached at room temperature to remove any natural signals present and then a laboratory dose of $54 \mathrm{~Gy}$ was administered to each aliquot. Luminescence measurement was made for 100 seconds at $125^{\circ} \mathrm{C}$ after preheat of $240^{\circ} \mathrm{C}$ for 10 seconds. As shown by the shine down curve, the photon counts were well above the detection limit (Fig. 3). Preusser et $a l$. (2006) used the first 20 seconds integral for comparison to characterize the luminescence properties from New Zealand Alps. Following that, a comparison has been made taking first 20 seconds integral from the shine down after stimulating for 100 seconds. The luminescence from 90-100 seconds integral was used for background subtraction. The net luminescence signal varies from 7000 to
30,000 (Fig. 3). If integration interval was reduced to the first 2 seconds of illumination time, luminescence signal varies from 1500 to 8000 . However luminescence from the first channel ( 0.4 seconds of illumination time) varies from 300 to 2000. Sample DP-8 which has a higher ratio of sediments from the host rock showed the lowest number of photon counts $(\sim 7000)$.

Comparing the luminescence counts and their sediment sources, DP-8 sediment has shown lowest number of photon counts ( $\sim 8000$ in first 20 seconds integral) which is explained by the maximum contribution of sediments $(62 \%)$ from the local rocks phyllite. As stated by Preusser et al., (2006), the low number of cycles of burial and erosion probably leads to weakly sensitized quartz, and this can be the reason of the low sensitivity of the sediments studied here as the sediments having maximum contribution from local rocks, have least photon counts.

A plot has been constructed between local host-rock sediment contributions against average photon yield for 20 seconds integral after giving 54 Gy laboratory dose (Fig. 3b). Luminescence photon counts are inversely proportional to the phyllitic contribution. The average photon count is small for DP-8 (maximum contribution from local rock phyllite) and large for DP-4 and DP-11 (having least contribution from local rocks). It indicates that luminescence properties are affected by mixing of local sediment contribution and from far upstream region. It will be a point of further research that how precisely, luminescence properties can be used as an indicator for sediment contribution from local rocks and the distal rocks.

\section{OSL thermal transfer}

A significant amount of transfer of charg may occur from deeper to shallower traps due to pre-heating of the natural OSL, which can cause overestimation of ages. $\mathrm{OSL}$ is measured while the aliquot is held at $125^{\circ} \mathrm{C}$ to minimize charge cycling through the $110^{\circ} \mathrm{C}$ TL trap and so increase the rate of decay of OSL signal. There are several examples of preheat plateau showing that the equivalent dose is insensitive to the preheat temperature in the range of $160-300^{\circ} \mathrm{C}$ (Murray and Olley, 1999; Murray and Wintle, 2000 and Roberts et al., 1999). Rhodes and Bailey (1997) determined a significant overestimation in equivalent dose $\left(D_{e}\right)$ in zero age glacio-fluvial samples from Greenland and attributed it to the thermal transfer of the OSL signals. Various authors have shown an increase in luminescence signal at higher temperature due to significant contribution due to thermal transfer (Banerjee, 2000; Wallinga et al., 2001).

The effect of thermal transfer was investigated in the samples. All aliquots were bleached using halogen lamp for 200 seconds at room temperature to remove any natural signal present in the sample. The equivalent dose $\left(D_{e}\right)$ was measured using SAR as suggested by Murray and Wintle (2000) with varying pre heat temperature ranging from $180^{\circ} \mathrm{C}$ to $280^{\circ} \mathrm{C}$ with steps of $20^{\circ} \mathrm{C}$ (Murray and Wintle, 2000). Preheat time was 10 seconds for each temperature. For each sample, 2 aliquots were prepared for each set of temperature. The linear fitting was used for dose growth curve. The results indicated that the 


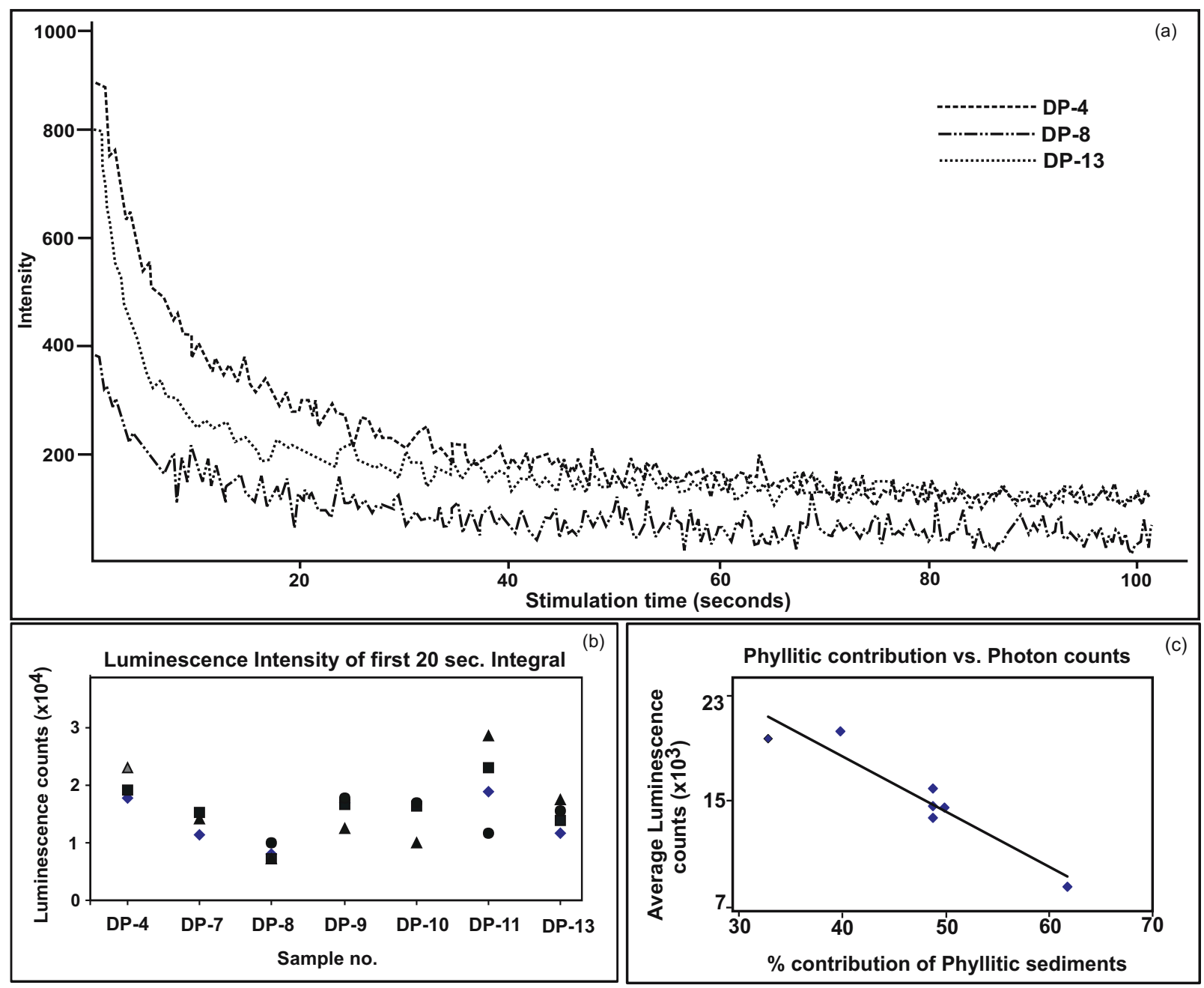

Fig. 3. (a) Shine down curves of sample DP-4 and DP-13. (b) Luminescence intensity of the various samples. The 7 mm aliquots were bleached and then given $54 \mathrm{~Gy}$ of laboratory beta dose followed by OSL measurement. The intensity above is the integral of first 20 seconds of the shine down curve. (c) The \% phyllitic composition was plotted against luminescence counts. The results show that photon counts are inversely proportional to phyllitic contribution.

amount of thermal transfer varies from $\sim 0$ Gy to $7 \mathrm{~Gy}$ (average $\sim 1-2$ Gy) (Fig. 4) and the value is high $(>5-15 \mathrm{~Gy})$ for a temperature of $260^{\circ} \mathrm{C}$ and higher. For sample DP-10, the thermal transfer is insignificant for a temperature range of $180-280^{\circ} \mathrm{C}$ (Fig. 4). However, for the samples DP-4, 9 and 10 , the thermal transfer value is high for temperature $280^{\circ} \mathrm{C}$. The thermal transfer effect was found to be small up to the temperature of $240^{\circ} \mathrm{C}$. It is likely that the samples received insufficient light exposure to empty the traps that are less light-sensitive and thermally shallow such as TL traps of $160^{\circ} \mathrm{C}, 240^{\circ} \mathrm{C}$ and $280^{\circ} \mathrm{C}$ (Murray and Olley, 2002). These samples when heated up to or close to these temperatures $\left(160^{\circ} \mathrm{C}, 240^{\circ} \mathrm{C}\right.$ and $280^{\circ} \mathrm{C}$ ) to release the trapped charge, a fraction of the released charge is re-trapped by the OSL traps; this gives rise to a low but finite amount of OSL signal, even though the sample was well bleached at the time of deposition. In the studied sample DP-4, the thermal transfer is present at $180^{\circ} \mathrm{C}$, which is probably coming as charge transfer from $160^{\circ} \mathrm{C}$ TL traps. However, in samples DP-9 and DP-10, this thermal transfer at low temperature too is negligible. The higher temperature is probably exciting the charges from deeper traps to the shallower traps caus- ing detectable luminescence signal as discussed by various authors (Banerjee, 2000; Wallinga et al., 2001; Bailey et al., 2001). These experiments allowed us to choose the appropriate preheat temperature when applied for routine dating.

\section{OSL Sensitivity changes}

\section{Dose recovery test}

In SAR, several cycles (6-7 cycles) of irradiation, preheat and luminescence measurement are repeated. In this process, the luminescence sensitivity changes are monitored using test doses and a recycled point equal to the first regeneration point is made to make sure that the sensitivity changes were monitored and remained within the accepted value of $10 \%$ (Murray and Wintle, 2000). Dose recovery is very important and reliable test required for determining the palaeodose using SAR. This test was applied on 8 aliquots of each sample. The aliquots were bleached for 200 seconds using halogen lamp to remove the natural OSL. A dose of 42 Gy was given to observe the variation in the precision of recovered dose. The re- 


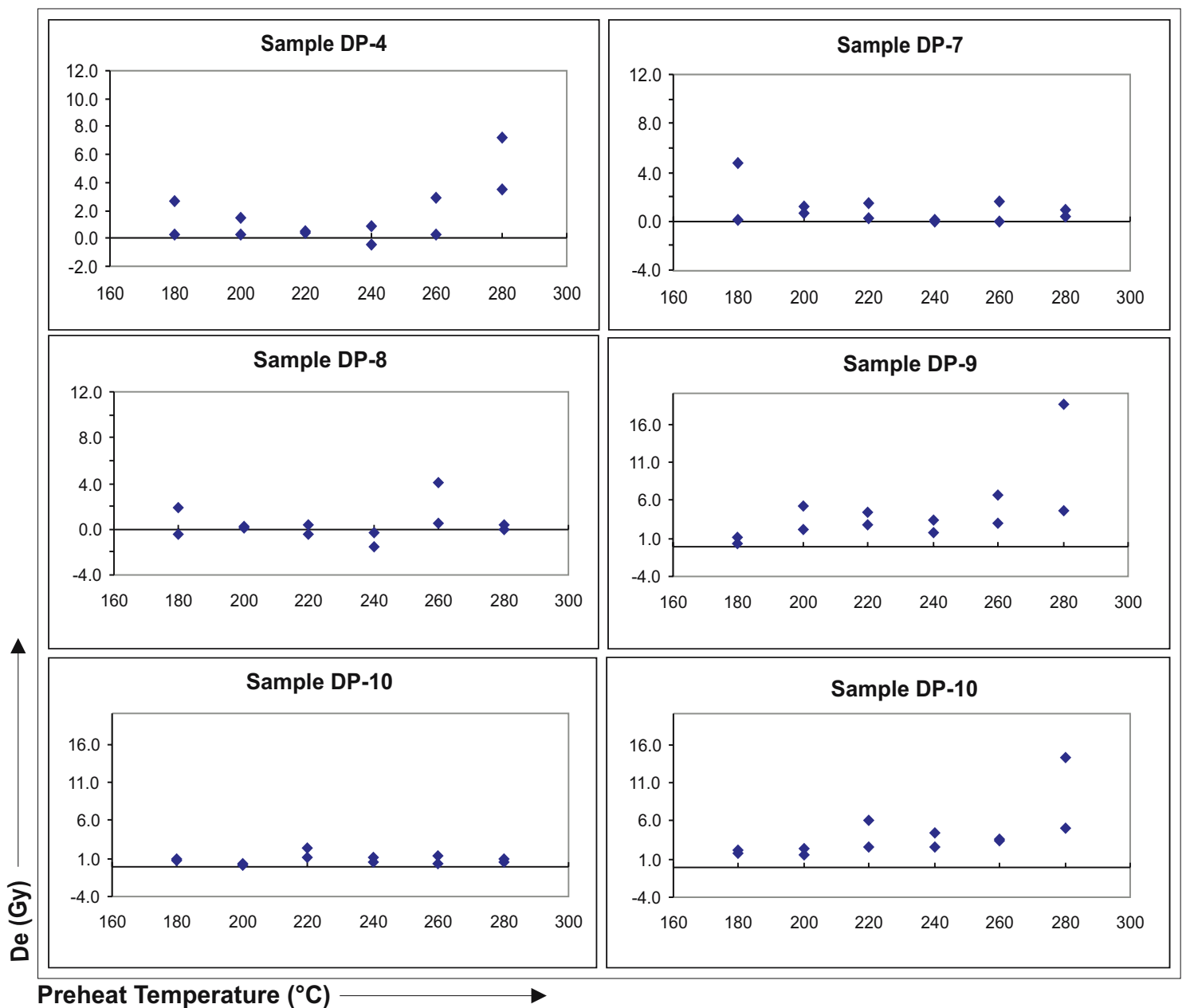

Fig. 4. Thermal transfer effect of the samples analyzed from Devprayag in Himalaya. Two aliquots were analyzed for each samples using SAR at ranging preheat temperature from 180 to $280^{\circ} \mathrm{C}$. In some samples the thermal transfer luminescence signal is significant and ranging up to $16 \mathrm{~Gy}$ at high temperature $\left(260-280^{\circ} \mathrm{C}\right)$.

generation doses were $30 \mathrm{~Gy}, 42 \mathrm{~Gy}, 54 \mathrm{~Gy}, 0$ Gy and 30 Gy again for the recycling point to check the correctness of sensitivity change monitoring.

The average $D_{e}$ was computed for all the recovered palaeodoses. The recovered doses are $40.8 \mathrm{~Gy}, 41.2 \mathrm{~Gy}$, $41.3 \mathrm{~Gy}, 41.5 \mathrm{~Gy}$ and $39.4 \mathrm{~Gy}$ that is within $5 \%$ of the given laboratory dose $(42 \mathrm{~Gy}$, considered as natural in this case) for the samples DP-7, DP-8, DP-9, DP-10 and DP-11 respectively. For samples DP-4 and DP-13, the averaged recovered doses are $37.1 \mathrm{~Gy}$ and $36.8 \mathrm{~Gy}$, still within $12 \%$ of the given laboratory dose. Some aliquots of DP-7 and DP-8 have shown $>20 \%$ higher values as compared to the given dose, the average have shown good recovered doses (Fig. 5). The preheat temperature can cause recuperation of the OSL signal (i.e. heating after OSL measurement can give rise to a new OSL signal, even in the absence of an ionizing radiation dose). It should be zero in the ideal case. This is tested by measuring the OSL without any regeneration dose. Then the OSL counts in this are compared with natural signal. In our samples, the amount of recuperation was $<2 \%$ of the sensitivity corrected natural luminescence (in this case, given laboratory dose of $42 \mathrm{~Gy}$ ). Thus recuperation is not a problem in the samples from the area of interest. All the

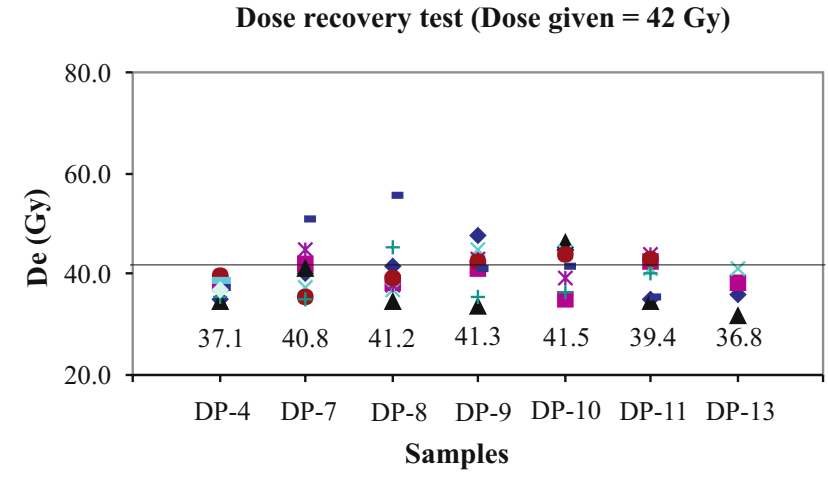

Fig. 5. Dose recovery test was carried out on 8 aliquots from each sample (DP-13 has only 4 aliquots). SAR was applied on bleached aliquots after irradiating with $42 \mathrm{~Gy}$. The data shows a good recovery of the laboratory dose and the average lies within $10 \%$ of the given dose; however, very few aliquots have shown considerable amount of deviation as seen in the sample DP-7 and DP-8. The number written below the symbols are the average dose of the recovered dose.

samples showed good recycling ratio (within 0.90-1.10) with very few exceptions of a range up to $0.85-1.15$. 


\section{Simulation of effect of repeated cycles of erosion and burial of sediments on OSL}

This test was performed to simulate the repeated reworking cycles of daylight exposure and irradiation of the sediment to see the effect of multiple cycles of erosion and sediments deposition on the sensitivity changes. Two sets of measurement were performed. In one set of experiments, first the aliquots were bleached using halogen lamp for 200 seconds at room temperature followed by irradiation of 84 Gy beta dose to 2 aliquots from each sample. The OSL measurement was done after $\sim 3$ hours without preheating to avoid any influence of thermal activation and incorporation of OSL signal from unstable $110^{\circ} \mathrm{C}$ OSL traps. This cycle was repeated for 5 times. In the other set of experiments, a second batch of aliquots were taken and bleached at room temperature. Two aliquots from each sample were irradiated for $84 \mathrm{~Gy}$ and OSL was measured similar to first set of experiments except that after irradiation, the aliquots were annealed at $450^{\circ} \mathrm{C}$, which helped to find out the effect of annealing on the sensitivity.

The results from first experiments shows a small but significant increase in the sensitivity (up to $25 \%$ in final stage after $4^{\text {th }}$ cycle, Fig. 6), which tells that the quartz have not reached a mature state of sensitivity indicating having probably young sedimentary history. However, even though the sensitivity is changing, it is well monitored by test doses in SAR (recycling ratio is within 10\% of unity) and found to be suitable for luminescence dating using SAR. Detectable luminescence counts, dose recovery and thermal transfer tests also support this.

Fig. 6 shows the effect of annealing (temp. up to $450^{\circ} \mathrm{C}$ ) on the sensitivity of the sample. The sensitivity increased by a factor of 4-5 in the samples DP-8, DP-9 and DP-13 (Fig. 7) during the first cycle of heating. Subsequent cycles of annealing increased the sensitivity by $20-25 \%$ in each step of its previous sensitivity. Similar results were found for rest of the samples. The results match well with the nature of the source rock because the

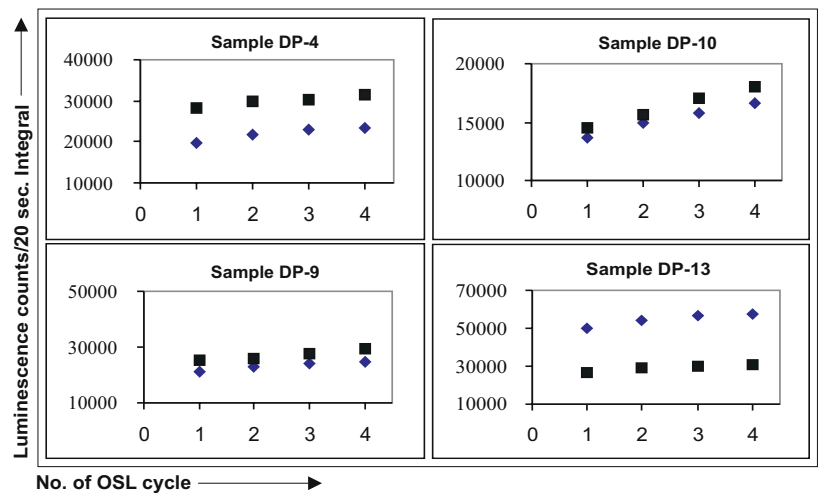

Fig. 6. Effect of OSL measurement on the sensitivity of the sample. Two bleached aliquots from each sample were irradiated with $84 \mathrm{~Gy}$ followed by OSL measurement. This experiment was performed to see the effect of number of cycle of deposition and erosion on the quartz grains. The data shows a small but certain increase in the photon counts (more clearly in sample DP-10), which indicates that the sample are not reached to a mature state of sensitivity. phyllite are weak metamorphosed rock (metamorphosed on low temperature and pressure). It also predicts that the quartz from the sediments coming from a high metamorphosed (high temperature and pressure) source rock (higher than phyllite) will be better sensitized. Based on the above studies a SAR protocol was designed to analyze the luminescence samples and thus establish chronology of the studied section after computing dose rates. The OSL-SAR dates agree well with the geologic setting and climatic history; however, these were discussed in detail by Srivastava et al. (2008).

\section{CONCLUSIONS}

The present study shows that even BGSL luminescence of quartz is of low intensity, it is sufficiently above detection limit and it allows the application of optical dating. The various tests discussed above allow to assess the OSL dating of such low intensity quartz. The present work concludes:

1) Quartz from phyllitic rocks is of low sensitivity. Luminescence counts per unit dose are inversely proportional to the percentage contribution of phyllite, which indicate that the luminescence characteristics represent the source rock characteristics.

2) Dose recovery tests hold good results and favor the application of SAR to these sediments.

3) Chandpur phyllite is exposed extensively in Kumaun Lesser Himalaya. Most of the samples dominate the quartz from phyllite rocks and thus it suggests that phyllite can be considered a source of quartz, which is suitable for optical dating.

4) Increase in OSL sensitivity (up to $25 \%$ ) on OSL measurement indicates a young sedimentary history; however, it does not restrict the applicability of optical dating techniques. The increased OSL sensitivity by a factor of 4-5 in the first annealing cycle indicates a low grade metamorphic history of the source rock, and supported by the nature of the source rock.

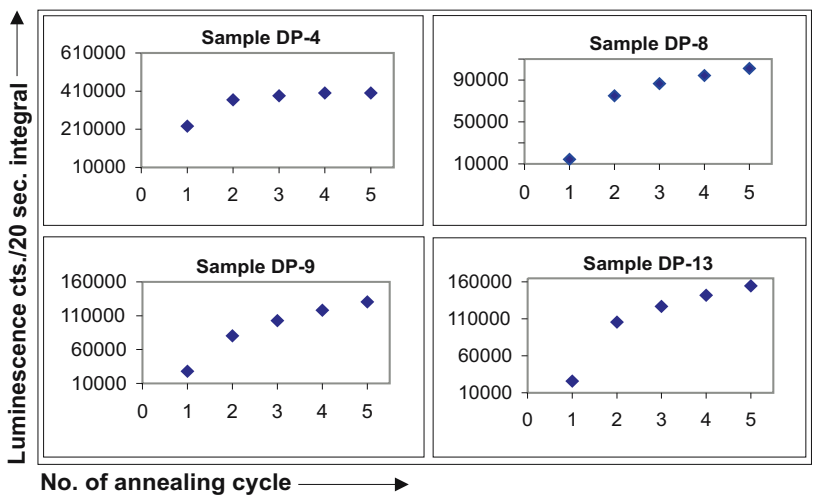

Fig. 7. Effect of annealing of the aliquots up to a temperature of $450^{\circ} \mathrm{C}$ on OS. In the first cycle, one aliquot from each sample was irradiated with $84 \mathrm{~Gy}$ followed by OSL measurement. In the consecutive cycles, aliquots were heated up to $450^{\circ} \mathrm{C}$ followed by irradiation and OSL measurement in the same manner. The data suggests a steep rise in sensitivity during first cycle by a factor of 4-5 and then slowed down the increase in sensitivity. 


\section{ACKNOWLEDGEMENTS}

The author acknowledges Prof. B.R. Arora, Director, Wadia Institute of Himalayan Geology, Dehradun, India for his kind support and encouragement throughout the work. Mr. V.P. Gupta is acknowledged for chemical treatment to the sediment samples.

\section{REFERENCES}

Ahmad T, Harris N, Bickle M, Chapman H, Bunbury J and Prince C. 2000. Isotopic constraints on the structural relationships between the Lesser Himalayan Series and High Himalayan Crystalline Series, Garhwal Himalaya. Bulletin of Geological Society of America 112: 467-477.

Aitken MJ, 1998. An introduction to optical dating. Oxford, Oxford University Press: 267pp.

Bailey SD, Wintle AG, Duller GAT and Bristow CS, 2001. Sand deposition during the last millennium at Aberffraw, Anglesey, North Wales, as determined by OSL dating of quartz. Quaternary Science Reviews 20(5-9): 701-704, DOI 10.1016/S02773791(00)00053-6.

Banerjee D, 2000. Thermal transfer and recuperation in quartz OSL and their consequences regarding optical dating procedure. In: Murthy KVR et al., eds., Luminescence and its applications. Luminescence Society of India C 1/2000: 86-93.

Banerjee D, Singhvi AK, Pande K, Gogte VD and Chandra BP, 1999. Towards a direct dating of fault gouges using luminescence dating techniques: methodological aspects. Current Science 77: 256-268.

Bilham R, Larsen K, Freymueller and Project Idylhim members, 1997. GPS measurement of present day convergence across the Nepal Himalaya. Nature 386(61-64): 61-64, DOI 10.1038/386061a0.

Burbank DW, 2005. Cracking the Himalaya. Nature 434(7036): 963964, DOI 10.1038/434963a.

Chamyal LS and Juyal N, 2005. Climatic events in southern Thar Desert margin and Higher Central Himalaya during the Last Glacial Stage (LGS): Possible linkages. Himalayan Geology 26: 241-252.

Fedo CM, Nesbitt HW and Young GM, 1995. Unraveling the effects of potassium metasomatism in sedimentary rocks and palaeosols with implications for palaeoweathering conditions and provenance. $\mathrm{Ge}$ ology 23(10): 921-924, DOI 10.1130/00917613(1995)023<0921:UTEOPM>2.3.CO;2.

Hodges KV, Wobus C, Ruhl K, Schidgen T and Whipple K, 2004. Quaternary deformation, river steepening, and heavy precipitation at the front of the Higher Himalayan ranges. Earth and Planetary science letters 220(3-4): 1-11, DOI 10.1016/S0012821X(04)00063-9.

Jaiswal MK, 2005. Optically stimulated luminescence dating of fluvial sediments: Application and Implications to Palaeoseismology and Palaeoclimatology. Unpublished $\mathrm{PhD}$ thesis, M.S. University of Baroda, Vadodara, India: 139pp.

Juyal N, Pant RK, Basavaiah N, Yadava MG, Saini NK and Singhvi AK, 2004. Climate and seismicity in the Higher Central Himalaya during the last $20 \mathrm{ka}$ : evidence from the Garbayang basin, Uttaranchal, India Palaeogeography, Palaeoclimatology, $\mathrm{Pa}$ laeoecology 213(3-4): $\quad 315-330, \quad$ DOI 10.1016/j.palaeo.2004.07.017.

Moska P and Murray AS, 2006. Stability of the quartz fast-component in insensitive samples. Radiation Measurements 41(7-8): 878-885, DOI 10.1016/j.radmeas.2006.06.005.

Mukul M, Jaiswal M and Singhvi AK, 2007. Timing of recent out-ofsequence active deformation in the frontal Himalayan wedge: Insights from the Darjeeling sub-Himalaya. Geology 35(11): 9991002, DOI 10.1130/G23869A.1.

Murray AS and Olley JM, 1999. Determining sedimentation rates using luminescence dates. In: Bruns P and Hass HC, eds., Determinations of sediment accumulation rates. Georesearch forum, Trans Tech publications, Switzerland: 121-144.

Murray AS and Olley JM, 2002. Precision and Accuracy in the Optically Stimulated Luminescence dating of sedimentary quartz: A Status review. Geochronometria 21: 1-16.

Murray AS and Wintle AG, 2000. Luminescence dating of quartz using an improved single aliquot regenerative-dose protocol. Radiation Measurements 32(1): 57-73, DOI 10.1016/S1350-4487(99)00253$\mathrm{X}$.
Nesbitt HW and Young GM, 1982. Early Proterozoic climates and plate motions inferred from major element chemistry of lutites. Nature 299(5885): 715-717, DOI 10.1038/299715a0.

Norrish K and Hutton JT, 1969. An accurate X-ray spectrographic method for the analysis of a wide range of geological samples. Geochimica et Cosmochimica Acta 33: 431-453.

Nesbitt HW and Young GM, 1989. Formation and digenesis of weathering profiles. Journal of Geology 97: 129-147.

Pal SK, 1986. Geomorphology of river terraces along Alaknanda valley, Garhwal Himalaya. Delhi, B.R. Publishing corporation: 158 pp.

Preusser F, Ramseyer K. and Schculhter C., 2006. Characterization of low OSL intensity quartz from the New Zealand Alps. Radiation

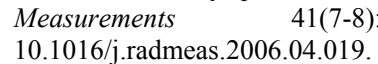

Pratt SB, Burbank DW, Heimsath A and Ojha T, 2004. Landscape disequilibrium on 1000-10,000 year scales Marsyandi River, Nepal, central Himalaya. Geomorphology 58(1-4): 223-241, DOI 10.1016/j.geomorph.2003.07.002.

Rhodes EJ and Bailey RM, 1997. Thermal transfer effects observed in the luminescence of quartz from recent glaciofluvial sediments. Quaternary Sciences Reviews 16(3-5): 291-298, DOI 10.1016/S0277-3791(96)00100-X

Roberts RG, Galbraith R, Olley JM, Yoshida H and Laslett G, 1999 Optical dating of single and multiple grains of quartz from Jinmium Rock shelter, northern Australia, Part II: Results and Implications. Archaeometry 41(2): 365-395, DOI 10.1111/j.14754754.1999.tb00988.x.

Senthil K, Wesnousky SG, Rockwell TK, Ragona D, Thakur VC and Seitz GG, 2001. Earthquake recurrence and rupture dynamics of Himalayan Frontal Thrust, India. Science 294(5550): 2328-2331, DOI 10.1126/science.1066195.

Singh IB, Jaiswal MK, Singhvi AK and Singh BK, 2003, Rapid subsidence of western Ganga plain during late pleistocene: Evidence from optical dating of subsurface samples. Current Science 84(3): 451-454.

Singhvi AK, Banerjee D, Pande K, Gogte V and Valdiya KS, 1994 Luminescence studies on Neotectonic Events in South-Central Kumaun Himalaya-A Feasibility Study. Quaternary Science Reviews 13(5-7): 595-600, DOI 10.1016/0277-3791(94)90083-3.

Srivastava P, Singh IB, Sharma M and Singhvi AK, 2003. Luminescence chronometry and late Quaternary geomorphic history of the Ganga plain, India. Palaeogeography, Palaeoclimatology, $\mathrm{Pa}$ laeoecology 197(1-2): 15-41, DOI 10.1016/S0031-0182(03)003845.

Srivastava P, Tripathi JK, Islam R and Jaiswal MK, 2008. Fashion and phases of late Pleistocene aggradation and incision in the Alaknanda River Valley, western Himalaya, India. Quaternary Research 70(1): 68-80, DOI 10.1016/j.yqres.2008.03.009.

Suresh N, Bagati TN, Thakur VC, Rohtash K and Sangode SJ, 2002. Optically stimulated luminescence dating of alluvial fan deposit of Pinjaur Dun, NW Sub Himalaya. Current Science 82(10): $1267-$ 1274.

Taylor SR and McLennan SM, 1985. The continental crust: its composition and 635 evolution. Oxford, Blackwell Scientific Publications: 312pp.

Thomas PJ, Reddy VD, Kumar D, Nagabhushnam P, Sukhija BS and Sahoo RN, 2007. Optical dating of liquefaction features to constrain prehistoric earthquakes in upper Assam, NE-India- some preliminary results. Quaternary Geochronology 2(1-4): 278-283, DOI 10.1016/j.quageo.2006.03.013.

Tripathi JK and Rajamani V, 2003. Geochemistry of Delhi quartzites: Implications for the source area provenance and weathering. Journal of the Geological society of India 62: 215-226.

Wallinga J, Murray AS, Duller GAT and Tornqvist TE, 2001. Testing optically stimulated luminescence of sand-sized quartz and feldspar from fluvial deposit. Earth and Planetary Sciences Letter 193(3-4): 617-630, DOI 10.1016/S0012-821X(01)00526-X.

Williams MAJ, Pal JN, Jaiswal MK and Singhvi AK, 2006. River response to Quaternary climatic fluctuations: evidence from the Son and Belan valleys, north-central India. Quaternary Sciences Reviews 25(19-20): 2619-2631,

DOI 10.1016/j.quascirev.2005.07.018.

Wobus C, Heimsath A, Whipple K and Hodges K, 2005. Active out-ofsequence thrust faulting in the central Nepalese Himalaya. Nature 434(7036): 1008-1011, DOI 10.1038/nature03499. 